\title{
Trainees on Technological Terrain: a Video Vignette-Based Tool to Teach E-Professionalism
}

\author{
Isheeta Zalpuri ${ }^{1}$ (D) Mirjana Domakonda ${ }^{2} \cdot$ Marika Wrzosek $^{3} \cdot$ Sandra DeJong $^{4}$
}

Received: 8 April 2020 / Accepted: 25 September 2020/Published online: 14 October 2020

(C) Academic Psychiatry 2020

As the digital revolution has unfolded, and smartphones and social networks have begun to permeate and expand the boundaries of medical practice, lapses in online professionalism and decorum have surfaced. In 2010, more than half of the US medical school deans reported breaches of professionalism related to online conduct [1], and $92 \%$ of responding American state medical boards (44 out of 48) reported having received at least one report of online professionalism violations, ranging from inappropriate online communication with patients to the use of Internet for inappropriate practice, including misrepresentation of credentials online [2].

In response to these professionalism breaches and the resulting sanctions, medical organizations published several reports and developed professional guidelines, standards, and consensus statements regarding responsible physician use of social media and the Internet [4] (Table 1). However, in an effort to promote and preserve open communication, access to care, and innovation, government agencies have been reluctant to over-regulate online content, placing the onus on physicians to "self-regulate" and comply with "voluntary codes of conduct" [5]. Indeed, this expectation for selfmonitoring and peer-based reporting of online unprofessional behavior is embedded in some professionalism guidelines (American Medical Association (AMA) American College of Physicians, and Federation of State Medical Boards (FSMB); Table 1).

Psychiatric trainees and experienced, well-established psychiatrists lie at the precipice of a generational crossroads in the mobile era. Psychiatric trainees are predominantly "digital

Isheeta Zalpuri

izalpuri@stanford.edu

1 Stanford University School of Medicine, Palo Alto, CA, USA

2 Hartford Hospital/Institute of Living, Hartford, CT, USA

3 Medical College of Wisconsin, Milwaukee, WI, USA

4 Cambridge Health Alliance, Boston, MA, USA natives," adept at utilizing and manipulating new technologies, while many seasoned psychiatrists are considered "digital immigrants," forced to adapt to the digital revolution midway through their career [6]. In this generational divide, the learner may be more technologically savvy, while the teacher's experience and expertise deem them more competent to recognize professionalism breaches. Inexperience in either realm could inadvertently have a negative impact on patient care and compromise physicians' personal and professional reputations. Licensing authorities in many jurisdictions can discipline physicians for unprofessional behavior, taking actions that range from a letter of reprimand to revocation of their medical license [7].

Despite the sensitive nature of their profession, psychiatrists cannot realistically be expected to abstain from social media use or refrain from cultivating an online presence. Indeed, there are benefits to learning these skills; for instance, Twitter and other social media platforms can help facilitate professional development and advocacy, provide information about trends in the field, and enhance knowledge about current treatment practices [8]. Thus, psychiatric training should dually highlight the potential privacy pitfalls of social media and educate trainees on how to appropriately interact with digital platforms.

There is a compelling need for effective e-professionalism training, yet few curricula are currently available to educators. In 2010, the American Association of Directors of Psychiatric Residency Training (AADPRT) Taskforce on Professionalism and the Internet developed a curriculum to advise psychiatric residents about professionalism and social media use. The authors created vignettes organized around nine professionalism issues - liability, confidentiality, and privacy; psychotherapy and boundaries; safety issues; mandated reporting; libel; conflicts of interest; academic honesty; netiquette; and professionalism remediation - for group discussion and/or individual study $[3,4]$. In another study, Flicklinger et al. designed a curriculum to enhance medical students' knowledge of professionalism and social media use. After completing a social media 
Table 1 Sample resources for educators

\begin{tabular}{|c|c|c|}
\hline Organization & Guidelines & Targeted audience \\
\hline $\begin{array}{l}\text { American Academy of Orthopaedic } \\
\text { Surgeons (created in 2012) }\end{array}$ & $\begin{array}{l}\text { Social media in healthcare-A primer for orthopedic surgeons } \\
\text { www.aaos.org/articlelink/?id=30249 }\end{array}$ & Orthopedic surgeons \\
\hline $\begin{array}{l}\text { American Association of Directors } \\
\text { of Psychiatry Residency Training } \\
\text { (created in 2011) }\end{array}$ & $\begin{array}{l}\text { Curriculum on professionalism and the Internet } \\
\text { DeJong SM, Benjamin S, Anzia JM, John N, Boland RJ, } \\
\text { Lomax J, and Rostain AL. Professionalism and the internet } \\
\text { in psychiatry: what to teach and how to teach it. Acad } \\
\text { Psychiatry. 2012. 36(5):356-362 [3] }\end{array}$ & Psychiatry training programs \\
\hline $\begin{array}{l}\text { American College of Physicians } \\
\text { (created in 2013) }\end{array}$ & $\begin{array}{l}\text { Online Medical Professionalism: Patient and Public } \\
\text { Relationships: Policy Statement From the American } \\
\text { College of Physicians and the Federation of State } \\
\text { Medical Boards } \\
\text { https://www.acpjournals.org/doi/10.7326/0003-4819-158-8- } \\
\text { 201304160-00100 }\end{array}$ & Physicians \\
\hline $\begin{array}{l}\text { American Medical Association } \\
\text { (created in 2018) }\end{array}$ & $\begin{array}{l}\text { Guidelines for Patient-Physician Electronic Mail and Text } \\
\text { Messaging } \\
\text { https://policysearch.ama-assn.org/policyfinder/detail/ } \\
\text { Guidelines\%20for\%20Patient-Physician\%20Electronic\%20 } \\
\text { Mail\%20and\%20Text\%20Messaging\%20H-478.997?uri= } \\
\text { \%2FAMADoc\%2FHOD.xml-0-4344.xml }\end{array}$ & Physicians \\
\hline $\begin{array}{l}\text { American Psychiatric } \\
\text { Association (created in 2009) }\end{array}$ & $\begin{array}{l}\text { The Internet in clinical psychiatry (resource document), } \\
\text { Joint Reference Committee } \\
\text { https://www.psychiatry.org/File\%20Library/Psychiatrists/ } \\
\text { Directories/Library-and-Archive/resource_documents/ } \\
\text { rd2009_Internet.pdf }\end{array}$ & Mental health providers \\
\hline $\begin{array}{l}\text { Australian Medical } \\
\quad \text { Association (created in 2011) }\end{array}$ & $\begin{array}{l}\text { Social media and the medical profession - } \\
\text { A guide to online professionalism for medical practitioners } \\
\text { and medical students. } \\
\text { https://ama.com.au/sites/default/files/Social_Media_and_the_- } \\
\text { Medical_Profession_FINAL.pdf }\end{array}$ & Physicians and medical students \\
\hline $\begin{array}{l}\text { British Medical Association } \\
\quad \text { (created in 2012) }\end{array}$ & $\begin{array}{l}\text { Social media use: Practice and ethical guidance for doctors } \\
\text { and medical students } \\
\text { https://www.bma.org.uk/advice/employment/ethics/social- } \\
\text { media-guidance-for-doctors } \\
\text { https://www.bma.org.uk/advice/employment/ethics/medical- } \\
\text { students-ethics-toolkit/12-students-and-social-media }\end{array}$ & Physicians and medial students \\
\hline $\begin{array}{l}\text { Federation of State Medical } \\
\text { Boards, Inc. (adopted as } \\
\text { policy in 2019) }\end{array}$ & $\begin{array}{l}\text { Model policy guidelines for the appropriate use of social } \\
\text { media and social networking in medical practice } \\
\text { www.fsmb.org-advocacy-policies-social-media-and- } \\
\text { electronic-communications.pdf }\end{array}$ & Physicians \\
\hline $\begin{array}{l}\text { International Society for } \\
\text { Mental Health Online and } \\
\text { Psychiatric Society for Informatics } \\
\text { (created in 2000) }\end{array}$ & $\begin{array}{l}\text { The suggested principles for the online provision of } \\
\text { mental health services http://ismho.org/resources/ } \\
\text { archive/suggested-principles-for-the-online- } \\
\text { provision-of-mental-health-services/ }\end{array}$ & Mental health providers \\
\hline $\begin{array}{l}\text { Massachusetts Medical Society } \\
\text { (created in 2012) }\end{array}$ & $\begin{array}{l}\text { Social media guidelines for physicians } \\
\text { http://www.massmed.org/Governance-and-Leadership/ } \\
\text { Committees,-Task-Forces-and-Sections/MMS- } \\
\text { Physicians\%2D\%2DGuide-to-Social-Media-(pdf)/ }\end{array}$ & Physicians \\
\hline $\begin{array}{l}\text { Ohio State University Medical } \\
\text { Center (created in 2009) }\end{array}$ & $\begin{array}{l}\text { Social media participation guideline } \\
\text { https://www.scribd.com/doc/27664236/Ohio- } \\
\text { State-University-Medical- } \\
\text { Center-Social-Media-Participation-Guidelines }\end{array}$ & $\begin{array}{l}\text { Ohio State University } \\
\text { Medical Center employees }\end{array}$ \\
\hline $\begin{array}{l}\text { Vanderbilt University } \\
\text { Medical Center }\end{array}$ & $\begin{array}{l}\text { Social media policy } \\
\mathrm{https}: / / \text { www.vumc.org/socialmediatoolkit/26923 }\end{array}$ & Vanderbilt employees \\
\hline
\end{tabular}

needs assessment, students participated in a workshop to learn social media professionalism skills. A complementary, longitudinal, social media-based curriculum to promote professionalism was subsequently created [9]. The authors found that personal-professional boundaries in the setting of social media use were an area of concern for students and that the workshop format and curricula were well received by the students.

In addition to some guidelines for online professional decorum (Table 1), there is a dearth of formal curricula that address violations that can arise in psychiatric 
training and practice. A 2015 anonymous survey of American adult psychiatry program directors and program administrators found that only $16 \%$ of the responders utilized any formal curriculum on e-professionalism; those that did most often used the published, case-based curriculum from AADPRT (Laothavorn J, Wrzosek MI, Finkenbine R, Jojic M, Zalpuri I. The professionalism efrontier: how are we teaching psychiatry residents to navigate pitfalls and privileges of online presence? Poster presented at the American Association of Directors of Psychiatric Residency Training Annual Meeting, March 4-7, 2015, Orlando, FL and the Association for Academic Psychiatry Annual Meeting, September 16-19, 2015, San Antonio, TX). The rationale for the underutilization of these guidelines/curricula was beyond the scope of this survey and not assessed. However, since the AADPRT curriculum was the most commonly used among programs that were using a formal curriculum, the authors wanted to capitalize on that finding and create supplemental material for the AADPRT curriculum, in the hopes that it would enhance its efficacy and expand its use. The authors created a series of three video vignettes as an innovative and interactive teaching tool to augment the AADPRT curriculum, help trainees gain a better understanding of e-professionalism breaches, as well as provide tools for chief residents, supervisors, and/or program directors on how to address them when they inevitably arise in training.

\section{Use of Videos as an Interactive Teaching Tool}

Educational lessons augmented with digital videos help pique learners' interest, engage their attention, and generate curiosity for the presented material $[10,11]$. By transcending the limitations of spoken and written didactics, videos allow educators to create and share educational content that is accessible to all learners, regardless of reading comprehension, mentalization, or auditory processing abilities [12]. They are valuable teaching tools [13] that generate learners' interest [14], effectively capture audience attention $[14,15]$, provide more information in a limited amount of time, and stimulate discussion during didactics. Use of technology additionally increases peer-to-peer interactions [16], which enhances learning through collaborative problem-solving and engaged discussion and promotes interactive learning beyond simply reading or watching content in isolation.

In order to capitalize on the promise of visual, interactive teaching tools, the authors designed a series of video vignettes to showcase and address online ambiguities that may arise during psychiatric training and practice. The videos are meant not only to serve as examples of professional pitfalls but also to guide trainees and educators on the use of appropriate language in approaching and addressing colleagues about these delicate topics. Ultimately, the videos aim to spur reflection and discussion in hopes of providing trainees and educators with a framework for approaching these issues as well as practical and sustainable tools in teaching and practice.

\section{The Video Vignettes}

Three video vignettes were developed to serve as an innovative and engaging approach to teach trainees and faculty on how to recognize and address nuanced online professionalism issues. In an attempt to broaden our dissemination platform, these videos are available for viewing online as individual media files on YouTube (Table 2). Although intended to serve as an interactive complement to the existing AADPRT Professionalism and the Internet curriculum, the video vignettes can also be used as standalone teaching modules. Each video features a unique scenario regarding an e-professionalism breach followed by a proposed solution to the dilemma. The variety of potential discussion points makes this format adaptable to numerous facets of curricular implementation. Ultimately, the authors hope that these videos will become viable tools for educators to empower trainees to confidently and successfully navigate the social media and e-professionalism frontier.

The videos commence with a conversation between a Chief Resident (either adult or child and adolescent psychiatrist [CAP]) and a junior resident. Table 2 lists the eprofessionalism concerns highlighted in each video and offers suggested questions and teaching points that can be used by faculty to guide trainee discussions.

\section{"The Dating Fellow"}

The Dating Fellow vignette highlights a potential boundary crossing between a resident and patient's family member. In this scenario, Arya (CAP Chief Fellow) has technical difficulties with her computer and is assigned Peter's (junior CAP resident) office while he is out sick with a migraine. When she turns on his computer, Arya sees Peter's dating profile open and notes a message from a patient's mother asking him on a date. The patient's mother notes that Peter plans to terminate her daughter's treatment next week. Arya is concerned and calls Peter. Peter is notably upset by the call and accuses Arya of invading his privacy. He states he has done nothing wrong, as he canceled the next appointment with his young patient and has not responded to her mother. Peter acknowledges that this 
Table 2 E-professionalism video vignettes with suggested discussion questions and teaching points

$\begin{array}{lll}\text { Video } & \begin{array}{l}\text { Professionalism } \\ \text { category }\end{array} & \text { Suggested discussion questions }\end{array}$

The Dating Fellow

https://youtu.be/_ Hkdbr8ZPyI

$\begin{array}{cc}\text { Confidentiality } & \text { - Did the resident violate HIPAA or patient privacy? } \\ \text { and privacy } & \text { - What are the rules about interacting with } \\ & \text { patients or families on social media platforms? } \\ & \text { - What are the rules about emailing or calling } \\ \text { patients from your personal accounts or devices? } & \text { - } \\ \text { Boundaries } & \text { networking sites at work? What about other } \\ \text { personal websites (i.e., shopping)? } & \text { Does your hospital have a policy about using } \\ \text { personal websites at work? } & \\ & \text { Should you separate your personal/professional } \\ \text { online presence? Can residents maintain a } \\ \text { professional social media page as a trainee? }\end{array}$
professional social media page as a trainee?

\begin{abstract}
Advocacy/altruism - Are you obligated to reschedule or disclose your reason(s) for cancellation to patients? Colleagues? Clinical staff?
\end{abstract}

The Blogging Resident https://youtu.

be/wDRsQgYUEPg
Netiquette Confidentiality
and privacy
- Do you feel comfortable discussing online professionalism issues with your supervisors/faculty? Why or why not?

- Are faculty trained to address online professionalism issues?

- Can you post patient information (photos, messages received, etc.) online?

- Does your hospital or HIPAA provide guidance on this?

- Does it make a difference if the content is de-identified or posted to your personal social media page versus a "public" page?

Netiquette

\author{
- Are you encouraged or provided \\ a forum to discuss sensitive, \\ patient-related topics? \\ - Do you have adequate training \\ and/or supervision on how to respond \\ to difficult in-person interactions?
}

Although the resident did not initiate the online communication in this scenario, if he responds to his patient's mother on the dating website, he could be violating patient privacy or hospital policy - Physicians have an obligation to maintain appropriate boundaries between their personal and professional life and should familiarize themselves with hospital policies on appropriate social media and Internet use at work

- Institutions might want to consider amending informed consent documents to include information on patient-physician communication (i.e., email, text, "friending"/following physicians on social media sites) if these do not already exist

- By canceling the termination session to avoid a discussion with his patient's mother, the resident did not consider his patient's best interest

- The resident should have discussed the situation and appropriate next steps with his supervisor, i.e., calling patient's mother to discuss the situation prior to termination session with patient

- Faculty development in e-professionalism is critical; apprehension about or avoidance of social media use can impede supervision and impact patient care

- Programs should consider identifying a faculty member versed in online professional issues to serve as a resource for all

- This scenario highlights that all online content is discoverable and reinforces need for trainee and faculty education on HIPAA and hospital guidelines about online conduct

- AAMC recommends using the "PRIP" (Privacy, Respect, Intent, Perception) criteria when sharing patient-related information online

- Here, the resident should have reflected on PRIP and considered the legal ramifications before posting the disparaging patient remarks

- Venting frustrations about patient encounters on a public forum is unprofessional

- Trainees should be provided with resources and access to trained supervisors who can help them process emotionally charged situations 
Table 2 (continued)

\begin{tabular}{|c|c|c|c|}
\hline Video & $\begin{array}{l}\text { Professionalism } \\
\text { category }\end{array}$ & Suggested discussion questions & Suggested teaching points \\
\hline $\begin{array}{l}\text { The Vacation } \\
\text { Flaunting Intern } \\
\text { https://youtu. } \\
\text { be/3CYrKTH_OGk }\end{array}$ & Integrity & $\begin{array}{l}\text { - Can you call out sick for personal } \\
\text { reasons unrelated to illness? } \\
\text { - Are you obligated to share your } \\
\text { reasons for taking a personal day } \\
\text { with covering colleagues? }\end{array}$ & $\begin{array}{l}\text { - This scenario underscores the need for early } \\
\text { and ongoing education about honesty and } \\
\text { accountability in practice, and the potential } \\
\text { impact of online unprofessionalism on } \\
\text { patient care and the workplace } \\
\text { - Given the discoverability and potential for } \\
\text { online interactions to be misinterpreted, } \\
\text { trainees and faculty should consider the } \\
\text { social/work implications involved with } \\
\text { social media use } \\
\text { - This scenario depicts how perceived } \\
\text { dishonesty and irresponsible behavior can } \\
\text { negatively impact clinical care and personal } \\
\text { relationships and underscores a physician's } \\
\text { responsibility towards his/her patients as } \\
\text { well as colleagues }\end{array}$ \\
\hline
\end{tabular}

AADPRT American Association of Directors of Psychiatry Residency Training, AAMC American Association of Medical Colleges, HIPAA Healthcare Insurance Portability and Accountability Act

situation has contributed to his headache but adds that he has not discussed the situation with his supervisor, who reportedly "discourages social media use." Arya empathically educates Peter about social media use and its potential impact on patient care. She encourages him to seek supervision on the matter from his direct supervisor or another mentor and to discuss the matter with his patient's mother in an informed and professional manner.

\section{“The Blogging Resident"}

The Blogging Resident vignette covers physician blogging, particularly relevant as this platform now also includes microblogging, or character-limited micro communications (e.g., Twitter). Sue, an adult psychiatry resident, is called to meet with her chief resident after Sue's co-residents read her blog post detailing a patient encounter in the emergency room. Even though Sue did not name the patient, she included enough descriptors in her post, including diagnosis, profession, and social history that the patient was easily identifiable. Sue's blog also identifies her as a psychiatry resident in Central Massachusetts, adding to the lack of anonymity, as there is only one program in the region. In her defense, Sue states that the post is private and only accessible to those with the link. The chief resident helps Sue understand how and why her blog post is unprofessional and a violation of patient privacy. The chief resident suggests several remediation strategies, specifically that Sue discusses the situation with her program director, both to inform him/her and to spur a broader, anonymous discussion with all of the trainees about the appropriate use of social media and how to ensure trainees abide by Health Insurance Portability and Accountability Act (HIPAA) when posting content online.

\section{"The Vacation Flaunting Intern"}

The Vacation Flaunting Intern vignette addresses the use of Facebook and how that may impact personal and professional boundaries. The scenario begins when the chief resident meets with Sam, a junior resident, after Sam has posted photos of himself at the beach on the same day that he called out sick from work. Sam is initially upset with the chief resident for "creeping his Facebook," which he perceives to be a violation of his privacy. The chief resident helps Sam recognize how content posted on social media platforms is easily discoverable and part of the public domain, and thus cannot be considered "private." He further discusses how being deceptive and taking a sick day for the purpose of vacation can be seen as unprofessional and unfair to his covering co-residents.

These videos have been presented as interactive workshops to professional peers at national conferences [2015 Association of Academic Psychiatry annual meeting, 2016 AADPRT annual meeting, 2016 American Academy of Child and Adolescent Psychiatry annual meeting, 2017 American Psychiatric Association annual meeting]. Overall, the workshops have been well received and spurred significant discussion and sharing of similar personal anecdotes. Participants have found the content to be educationally useful, noting that the content learned would advance their knowledge of the topic and change their practice. Each session incorporated some didactic teaching on e-professionalism, viewing of video vignettes, and finally small and large group discussion. The discussion always included components of 
harnessing classic principles of practice (professional decorum, respect for boundaries, appropriate communication) and adapting them to current technological trends. The objectives were to increase awareness of how social media use can impact patient care and demonstrate how practicing physicians, especially psychiatrists, can honor classic concepts without having to spurn electronic communication and social media in their personal and professional lives. The authors have also used these videos in didactics and received informal positive feedback about how the interactive and engaging nature of the vignettes made the discussions lively and helpful.

\section{Potential Teaching Methods}

These videos are one example of how learners can evoke reallife examples to enhance their medical school and/or residency training skill sets. Learners may then generate their own vignettes to discuss. These videos can help learners appreciate how social media use can impact professionalism, understand the implications of social media-driven professionalism breaches on practice, and, by way of directive dialogue, demonstrate at least one way to address these issues outside the classroom. They can supplement or enhance existing curricula on social media and professionalism in a variety of ways. For instance, although the videos showcase one example of how to discuss a social media breach, the instructors may choose to only show the scenario and ask trainees to role-play possible discussions before presenting the suggested approach. Since these videos demonstrate potential language one can use to address these issues, they can assist the learners to go from "observer of an abstract scenario" to one where they are empowered to approach these scenarios in independent practice. As with any teaching tool, the authors recommend instructors to view the videos in their entirety before presenting them to the residents or faculty. Authors share some questions that can enhance engagement and be used during discussion to stimulate discourse on numerous topics, making the lecture more interactive (Table 2). These can be customized to specific situations.

\section{Future Directions}

As the next step, the authors plan to implement these video vignettes in 3-5 training programs as a more formal "pilot" program, from which the authors would hope to develop a formalized video vignette-based curriculum to facilitate teaching e-professionalism in training. The pilot will involve preand post-curricula surveys to assess the ease of implementation and efficacy of this model to enhance trainees' knowledge of e-professionalism.

\section{Conclusion}

Psychiatric residents are increasingly digital natives, and digital technology is now inextricably linked with interpersonal communication. While the decision to engage with social media is personal, the impact of that choice on professional boundaries is important and warrants concerted education and training. Indeed, Zalpuri et al. created an Accreditation Council for Graduate Medical Education framework for social media/networking competencies for psychiatric assessment and treatment, given that novice and more advanced learners, alike, require competencybased education on this topic [17]. Regardless of their personal preferences and comfort with online communication methods and social media platforms, educators have an obligation to inform and arm their trainees with the critical thinking skills necessary to conscientiously navigate the digital realm. In residency, trainees have a unique opportunity to engage supervisors with their digital world and seek individual guidance on how to translate professional to e-professional, to snail mail to e-mail, and private opinion to public "likes." Supervisors, in turn, have a unique chance to learn from their trainees and seek to understand the draw of tweets and hash tags. In addition, a video vignette series, while not exhaustive, provides a concrete example of how to address an abstract concept, and, in combination with the AADPRT written materials, offers the opportunity for multimodal learning. The authors hope that the use of video vignettes promotes ongoing discussion and creation of toolkits as programs around the country grapple with how to best supplement their existing curricula to keep up with the dynamic technological landscape.

It is no longer a question of "should" physicians engage in social media and use digital technology; that ship has long sailed. The goal is now to effectively equip the next generation of psychiatrists with the tools necessary to apply classic principles of professionalism to a brave new technological world.

Acknowledgments The authors would like to thank Drs. Juntira Laovathorn and Patrick Gibbons for their superb acting skills and help in developing the videos and Alex Boyes, who helped edit the videos. The authors would also like to acknowledge Dr. Sheldon Benjamin for being the original inspiration for this work.

\section{Compliance with Ethical Standards}

Disclosures Drs. Zalpuri and Wrzosek have no conflict of interest. Dr. Domakonda receives or has received research support from Janssen, Otsuka Pharmaceuticals, NeuroRx, Inc., and National Institute on Mental Health. She serves on the scientific advisory board for Novamind Ventures, Inc. and also on the advisory board for Realize Your Beauty, Inc. Dr. DeJong receives royalties from Elsevier for a book on e-professionalism in healthcare. She receives payment in kind for work related to psychiatric education and professional leadership from American Academy of Child and Adolescent Psychiatry, Accreditation Council for Graduate Medical Education, The American College of Psychiatrists, American Association of Directors of Psychiatric Residency Training, and American Psychiatric Association. She is an employee of Cambridge Health Alliance. 


\section{References}

1. Chretien KC, Greysen SR, Chretien JP, Kind T. Online posting of unprofessional content by medical students. JAMA. 2009;302(12): $1309-15$.

2. Greysen SR, Chretien KC, Kind T, Young A, Gross CP. Physician violations of online professionalism and disciplinary actions: a national survey of state medical boards. Research Letter. JAMA. 2012;307(11):1141-2.

3. DeJong SM, Benjamin S, Anzia JM, John N, Boland RJ, Lomax J, et al. Professionalism and the internet in psychiatry: what to teach and how to teach it. Acad Psychiatry. 2012;36(5):356-62.

4. DeJong SM. Professionalism and technology: Competencies across the tele-behavioral health and e-behavioral health spectrum. Acad Psychiatry. 2018;42(6):800-7.

5. Hughes PP, Goldstein MM. Privacy, security, and regulatory considerations as related to behavioral health information technology. Behavioral Healthcare and Technology: Using Science-Based Innovations to Transform Practice. 2014. Nov 10;224.

6. Paul Taylor, Carroll Doherty, Kim Parker, Vidya Krishnamurty. Millenials in adulthood: pew social trends. http://www. pewsocialtrends.org/2014/03/07/millennials-in-adulthood/. Accessed 31 Aug 2020.

7. Federation of State Medical Boards. http://www.fSM/Nb.org/ Media/Default/PDF/FSM/NB/Advocacy/pub-social-mediaguidelines.pdf. Accessed 1 Jun 2018.

8. Liu HY, Beresin EV, Chisolm MS. Social media skills for professional development in psychiatry and medicine. Psychiatr Clin. 2019;42(3):483-92.

9. Flickinger TE, O'Hagan T, Chisolm MS. Developing a curriculum to promote professionalism for medical students using social media: pilot of a workshop and blog-based intervention. JMIR Med Educ. 2015;1(2):e17.

10. Graham P, Johnson H. Stimulating curiosity to enhance learning. GESJ: Educ Sci Psychol. 2011;2(19):24-31.

11. Mady MA, Baadel S. Technology-Enabled Learning (TEL): YouTube as a ubiquitous learning aid. J Inf Knowl Manag. 2020;19(01):2040007.

12. Mechling L. The effect of instructor-created video programs to teach students with disabilities: a literature review. J Spec Educ Technol. 2005;20(2):25-36.

13. Lewis J, Allan S. Physician-patient boundaries: professionalism training using video vignettes. MedEdPortal. 2016. Publication: 10412.

14. Tversky A, Kahneman D. The framing of decisions and the psychology of choice. Environmental Impact Assessment, Technology Assessment, and Risk Analysis. Berlin: Springer; 1985. p. 107-29.

15. Fox G. Teaching normal development using stimulus videotapes in psychiatric education. Acad Psychiatry. 2003;27(4):283-8.

16. Gulek J, Demirtas H. Learning with technology: the impact of laptop use on student achievement. J Technol Learn Assess. 2005;3(2): 3-6.

17. Zalpuri I, Liu HY, Stubbe D, Wrzosek M, Sadhu J, Hilty D. Social media and networking competencies for psychiatric education: skills, teaching methods, and implications. Acad Psychiatry. 2018;42(6):808-17.

Publisher's Note Springer Nature remains neutral with regard to jurisdictional claims in published maps and institutional affiliations. 